\title{
Challenges In Widening Participation Outreach: Is Enough Being Done To Tackle The Under-Representation Of Low-Income Students In Medicine?
}

This article was published in the following Dove Press journal:

Advances in Medical Education and Practice

\author{
Akinyemi Apampa' \\ Angela Kubacki ${ }^{2}$ \\ Utkarsh Ojha' \\ Jinpo Xiang'
}

'Faculty of Medicine, St George's University of London, London, UK; ${ }^{2}$ Institute of Medical and Biomedical Education, St George's University of London, London, UK
Correspondence: Akinyemi Apampa Faculty of Medicine, St George's University of London, Cranmer Terrace, Tooting, London SWI7 ORE, UK

$\mathrm{Tel}+447853086285$

Emailm1602372@sgul.ac.uk

\begin{abstract}
Widening Participation (WP) in medicine refers to all theory, activities and policy concerned with removing barriers to entering medical school for students from lower income and under-represented backgrounds. Medical schools and other institutions including; the Medical Schools Council, the Office for Fair Access, the Higher Education Funding Council for England, have been committed to improving Widening Participation for more than a decade. As senior medical students and academics, we have been actively involved with WP work at our respective medical schools and in conjunction with the British Medical Association (BMA) and the Medical Schools Council (MSC). Yet, we have observed over the years that the pace of change seems sometimes stuttering and stagnated. Here, we have investigated the reasons why there is still such a significant under-representation of students from lower income backgrounds in medicine. In order to make the medical student intake representative of the general population, the number of applications from lower income students would need to increase five-fold. This would require a great scaling up of WP outreach work. Critical analysis demonstrates that medical schools and the other key institutions in medical education have made many nominal commitments to WP, but have yet to make any commitments that are truly binding. This may be due to the institutions lack of belief in their own capacity to scale up WP Outreach sufficiently to achieve success. Ultimately binding commitments will be needed to secure a representative intake of medical students. In order for institutions to be willing to move towards such commitments, evidence-based success in WP must first be demonstrated through collaboration on specific projects that are scalable, sustainable and impactful.
\end{abstract}

Keywords: widening access, widening participation, outreach, medical school, social inequality

\section{Introduction}

This paper aims to review strategic challenges to Widening Participation (WP) Outreach in Medicine. The Office for Fair Access ([OFFA] and the Higher Education Funding Council for England [HEFCE] were merged into the new Office for Students [OFS] in 2018. At the time of writing, the merger is still in process. Therefore, this paper refers to OFFA and HEFCE, though from 2019 their roles will be fulfilled by OFS) defines Widening Participation (WP) as "Removing the barriers to higher education, including financial barriers, that students from lower income and other under-represented backgrounds face". 2 This paper focuses particularly, though not 
exclusively, on students from lower income backgrounds, 'Widening Participation (WP) students'. OFFA defines '[WP] Outreach' as

Activity by universities and colleges that helps to raise awareness, aspirations and attainment among people from disadvantaged backgrounds, e.g summer schools that give a taste of university life, homework clubs for pupils who may not have anywhere to study at home, or universities forming and sustaining links with employers and communities. ${ }^{2}$

The importance of WP Outreach in medicine is implicit in the statement made by the British Medical Association (BMA) that

In contrast [to the challenge of increasing the number of women in medicine], the struggle for social mobility within the [medical] profession is still in its infancy, although the chief obstacle is not outright opposition so much as inertia. ${ }^{1}$

Historically, overtly sexist beliefs and institutions created active barriers against women entering the medical profession. $^{14}$ In the present day, with much of this opposition removed, there are now more women than men in medical schools (notwithstanding that other types of discrimination against women in medicine still exists). ${ }^{14}$

Evidently, there were more than enough women with the resources, incentive and academic preparation to enter medicine, once their entry was no longer opposed. In contrast, whilst there is not active opposition against students from lower income backgrounds, there is a shortage of such students with the resources, incentive and academic preparation. This is why the "inertia" mentioned above is such a problem and why there is a great need for robust Widening Participation Outreach work to actively recruit students from low-income backgrounds.

In order to make clear the aims of Widening Participation Outreach this article outlines a model of WP Outreach, which recognises three fundamental ways in which WP Outreach can be improved:

Scale: increase the number of WP students engaged;

Impact: increase the proportion of those students engaged who make successful applications to medical school;

Sustainability: making sure work has sustainable funding and is integrated into medical schools' structures in the long term.
This model was inspired by common approaches to best practice in the third sector. ${ }^{8}$

\section{Objectives}

Part 1 outlines the size of the challenge for WP Outreach.

Part 2 analyses the wider context and positions of the key stakeholders in WP Outreach, which the authors believe is integral to understanding why the challenges to WP Outreach remain so large. Particularly, we examine why nominal commitments to improving WP Outreach may not translate into real success in tackling the great challenge laid out in Part 1.

\section{Part I: How Big Is The Challenge For WP Outreach?}

There are significant challenges to develop a large-scale sustainable WP outreach programme. Indeed, research commissioned by the Medical Schools Council in $2014^{3}$ showed that:

(a) Approximately half of schools and colleges in England had no applicants for medicine

(b) $80 \%$ of applicants came from only $20 \%$ of schools and colleges, which were mostly selective schools and large sixth form colleges

Whilst this captures the extent of the challenge, it should not be seen as an insurmountable problem. Rather, a closer examination of the numbers must be conducted to clearly outline what must be done to achieve a more representative body of medical professionals.

In 2015-16, there were 33 (several new medical schools were announced in 2018) UK medical schools with a national intake of 5880. ${ }^{4}$ This gives an average intake of 178 students per medical school. Higher Education Statistics Agency (HESA) data show that National Statistics Socioeconomic Classification (NSSEC) groups 4 to 8 , made up approximately $10 \%$ of medical students in 2012-2013 academic year. ${ }^{3}$ Whilst in the 2011 Census they make up very roughly $50 \%$ of the population of the United Kingdom. ${ }^{5}$ For WP Outreach schemes to make medical students proportionately representative of the population there would need to be a fivefold increase in the number of such students.

How, in practice, might this goal of increasing WP student numbers five-fold be achieved by applying the model of Impact, Scale and Sustainability? Consider a 
medical school running intensive WP Outreach Summer Schools which currently engage with 500 students per year, of which 10 students make successful applications to study medicine. Focusing on Impact, the medical school might aim to improve the efficacy of their program such that five times as many students are successful in their applications (with the same number of total students). Focusing on Scale instead, the same medical school might aim to make the original program reaches five times as many students (with the same original success rate). In either case the number making successful applications rises from 10 to 50. Focusing instead on Sustainability, the medical school might aim to run the program at one-fifth of the current cost and invest the savings in other WP Outreach activities. A focus on Sustainability would also ask what the medical school would need to do to ensure such changes were long term and how the school itself might need to change to accommodate the change in student intake.

\section{Part 2: State Of Play In WP Outreach \\ Are Medical Schools Prioritising WP Students?}

The information available directly through the main websites of the 33 long-established public medical schools in the UK (five new medical schools were announced in 2018) in the UK was reviewed to assess commitments to recruiting WP students. Specifically, the core medicine course information webpages and medicine-specific Widening Participation webpages were reviewed to assess whether they gave any specific numerical targets (percentage or actual numbers) for a) WP students to be recruited to the courses in coming years or b) the numbers of WP students successfully recruited in previous years. The same webpages were also reviewed to assess whether there were any mention of WP Outreach programmes or WP-targeted Foundation Year courses (courses where applicants from WP backgrounds who may not meet the academic entry criteria for the core medicine courses can apply instead to one year Foundation course, which, if successfully completed, allows them to move on to the core medicine course).

Every medical school makes reference to a WP Outreach program of some sort (though not always medicine-specific). Only one school, Aston Medical School, Birmingham makes clear on its website specific numerical aims to "offer $40 \%$ of our UK/EU places each year to students who meet specified widening participation criteria" for its core medicine course. ${ }^{15}$ University of Sheffield reserves all 15 places of its Graduate Entry Medicine program solely for students from Widening Participation backgrounds. ${ }^{18}$ None of the other 31 medical schools state any binding commitment to reserve places on their core medicine program for students from WP backgrounds. ${ }^{16-50}$

12 medical schools offered Foundation Year courses, which can be seen as an active commitment to WP. Kings College London specifies

For 2018 entry 77 students will be enrolled onto the EMDP [its Extended Medical Degree Programme for Widening Participation], designed for students from nonselective state schools ... who may not have reached their full academic potential. ${ }^{16}$

University of Southampton's website outlines it has the "Second longest-running widening participation programme in the UK ... [with] ... A small cohort of approximately 30 students". ${ }^{17}$

It is promising that so many medical schools have WP Outreach programs and Foundation programs. However, Foundation programs are not always entirely targeted at students from WP backgrounds and do not guarantee a place on core medicine courses. ${ }^{51}$ Unfortunately, despite the promising number of WP Outreach programs and Foundation Year courses, the fact that only one medical school made any specific numerical target for the proportion of WP students entering its core medicine course is reflective of the lack of binding commitments put upon medical schools to recruit WP students.

\section{Office For Fair Access (OFFA)}

One might hope that OFFA Access Agreements (annually, every university must set out plans for how they will recruit and support WP students. These plans, the "Access Agreements", must be approved by OFFA in order for the university to be allowed to charge full tuition fees) would shed more light on the details and success of WP Outreach at individual medical schools. Unfortunately, what is often forgotten about WP in medicine is that it usually sits within WP for a university as a whole. That means that WP Outreach for medicine will make up only a very small part of a university's WP portfolio. As such, most university OFFA agreements do not provide specific details of WP for medicine. This essentially means there is in effect no statutory obligation on medical schools to fill any compulsory minimum number of WP student places. 
Furthermore, it should be noted that failure to meet the targets set in OFFA agreements has never led to a reduction in funding, in fact, OFFA states: "We would not impose a sanction solely because a university or college has not met the targets or milestones it has set itself" ${ }^{6}$ In fact, whilst OFFA has the power to sanction or fine universities for not upholding their agreements, it has never had what it classifies as a "major breach". In the handful of "breaches to agreements" recorded in its history, these have nearly all been about the mischarging of fees - never about failure to succeed in Widening Participation. ${ }^{7}$ The lack of specificity for medicine and the lack of any real teeth ${ }^{39}$ makes it unlikely OFFA could have a significant impact on WP Outreach in medicine. It is not clear whether OFFA's absorption into the new Office for Students (OFS) will make it more or less effective.

\section{Medical Schools Council (MSC)}

Fortunately, where there is a paucity of detailed information from medical schools or OFFA agreements, the Medical Schools Council (MSC) does have a voice. The several reports from the MSC Selection Alliance, ${ }^{3,9-11}$ specifically focusing on Widening Participation provide a wealth of information on broadly applicable principles for WP outreach and national trends in WP. For example, the MSC supports contextualised offers, foundation programs, mini-multiple interviews (MMIs), and long-term WP Outreach aimed at different age groups. ${ }^{3}$ The MSC also gives a national picture of WP applications and entrants to medical school based on various WP metrics: social class, parental education, ethnicity, etc. ${ }^{3,10}$ Finally, the MSC has suggested some promising approaches that a few schools are beginning to trial, including; collaboration between medical schools, targeting cold spots and developing a shared evidence base. ${ }^{10}$

Despite these efforts, increases in number of WP students entering medicine still remain limited. It should be remembered that the MSC itself is actually a very small organisation dependent on voluntary contributions of its member schools and very few in house staff. It also has no statutory powers over medical schools. The MSC's limited ability to play an active role in turning recommendations into action may explain the limited impact of its work to date.

It is evident that whilst the MSC has contributed to publishing national data on $\mathrm{WP}^{3,10}$ it has yet to directly support publication of individual schools' data on WP, which would be necessary to see how schools are improving (or not) and which would provide a foundation to asses which are the most effective interventions. No organisation has yet published or suggested direct approaches to proper impact evaluation (e.g. comparative studies or randomised control trials) to show what really works by comparing different approaches within or between medical schools. This is surprising given that the outcome - successful applications to medicine - is relatively easy to measure.

As well as working out "what works", there is also the question of "what does not work so well". There has not yet been any suggestion by the MSC or others about approaches that do not appear to work so well. Given the overall evidence showing that WP is not working well in medicine, some suggestions on approaches schools should probably stop doing could be very helpful.

Finally, while the MSC strongly supports collaboration between medical schools on WP, this has not happened yet. MSC gave itself an amber rating for achieving its selfset recommendation: 'The MSC should consider and test potential collaboration between medical schools on outreach programs'. ${ }^{10}$ The amber rating is given for work on teachers and careers advisers conferences. Given the need and the potential for collaboration on WP Outreach there may be a very substantial jump needed from Amber to Green. MSC is in an ideal position to actively facilitate collaboration between medical schools on WP, which should go beyond conferences to active collaboration on WP Outreach work that will have economies of scale and scope for shared ambitions of WP Outreach.

These challenges may also relate to the nature of MSC as a membership organisation. Some actions will be burdensome to its members and others might make certain members look better or worse than their competitors. Unfortunately, putting a burden on medical schools and identifying which medical schools are succeeding and which are falling behind on WP are minimum requirements for making real progress.

\section{General Medical Council (GMC)}

In contrast to the MSC, the GMC is a large organisation with a statutory regulatory role over medical education. Unfortunately, it does not have a great deal to say about Widening Participation Outreach work. This is understandable as the GMC bears the mammoth responsibility of protecting equality and diversity for all those already in medical school and all those in the medical profession. The GMC's 2014-17 Equality, Diversity and Inclusion Strategy ${ }^{12}$ includes work on 
disability and differential attainment (lower pass rates of certain groups, e.g., black and minority ethnic (BME) students and doctors) in medical schools, but there is no mention of Widening Participation. The GMC is primarily concerned with those already at medical schools, but has less regulatory concern or capacity for WP applicants (or the lack of them). The question raised then is whether the GMC should either take a more active role in regulating medical schools' recruitment itself or pass over more responsibility or resources to organisations like the MSC, that are looking in more detail at applications and entry to medical schools.

\section{Resources}

For all the vocal commitments of institutions and organisations for increasing WP in medicine, there is yet to be seen any proportional increase in the resources. Again, it must be remembered that a greater portion of the WP budget for a university will be focused on many courses other than medicine. The hours of WP staff also are spread across WP for multiple courses, with few universities having WP staff dedicated solely to medicine. This lack of resources must also be compared to the great expense spent by non-WP students on private tuition, books, summer schools and work experience placements to help them secure limited places available.

\section{Higher Education Funding Council for England (HEFCE) and New Medical School Places}

One of the greatest opportunities to increase WP places in medical schools was in the allocation of the 1500 new Higher Education Funding Council for England (HEFCE) funded places. Unfortunately, despite efforts from the Medical Schools Council and the BMA Medical Students Committee to secure a requirement of $100 \%$ of these places (at existing medical schools) going to WP applicants, HEFCE refused to put in any compelling statutory requirements for WP.

Encouragingly, the bidding process specified WP criteria as a top priority for allocation of places. ${ }^{13}$ It is yet to be seen whether these non-binding requirements will have any effect. Unfortunately, without strict requirements the effects are uncertain and the historical precedent is not promising. Many medical schools are already failing to meet existing non-binding limited targets set through OFFA. There is a lack of WP applicants ready to meet entry criteria and an excess of non-WP applicants ready to meet entry criteria.
Hence, without binding requirements, it is likely that schools will be no better at filling these new places with WP students than they are at filling existing places with WP students. This could mean that the new places make WP students an even smaller proportion of the total student population, further diluting the already thin mix of diversity at medical schools.

\section{Summarising The State Of Play: Non-Committal}

This analysis of the state of play and the positions of the key institutions: medical schools, OFFA and HEFCE, the Medical Schools Council, is encouraging in the nominal and vocal commitments to WP. Sadly, however, the lack of success thus far and the absence of any binding agreements or quotas for numbers of WP students or any strong evidence of what works in WP Outreach reveals that, in practice, the pursuit of increased WP students has been somewhat non-committal. This might stem from a fear of failure or a lack of belief in success. Medical schools may understandably be fearful of committing themselves to WP targets they cannot meet and HEFCE's refusal to make solid targets may reveal that they do not believe that a drastic increase in WP students is the most desirable or important outcome for the allocation of new medical school places.

\section{Conclusion}

Ultimately, binding minimum requirements aka quotas for WP places are the definitive solution. Only this will guarantee the five-fold increase in numbers of WP students needed to make the medical profession representative of the population it serves. The analysis of the State of Play in WP reveals that while the key institutions are all vocal in their support of WP, in practice this support remains non-committal due to fear of failure and lack of belief in the possibility of success. This lack of commitment is apparent from individual medical schools' WP policies and OFFA agreements (it remains to be seen as whether this will change with OFFA's reorganisation into the OFS). Worryingly, national policy is also non-committal. This was revealed by the failure to put any binding minimum requirements for WP places in the recent addition of 1500 new HEFCEfunded medical school places, which now risk further diluting diversity in medical schools.

To overcome this fear of failure and lack of belief in success, new approaches to WP Outreach are needed to 
boost confidence in and demonstrate the achievability of success. These new approaches must strategically aim to improve Impact, Scale and Sustainability of WP Outreach. They must be collaborative and must contribute to a shared evidence base. The strategic institutions linking and regulating medical schools - the Medical Schools Council, the GMC - must become more prescriptive and more active in encouraging schools to work together on such new approaches. (They must also encourage schools to drop unilateral approaches that have not been working.)

Once all stakeholders in medical education begin to collaborate on specific shared approaches to WP Outreach, they may begin to have more confidence in success and may feel less individually afraid of committing to binding targets for WP. Finally, real binding targets for WP will make it easier to properly link resources, e.g. OFFA (or future OFS) funding to successful WP programs.

\section{Disclosure}

The authors report no conflicts of interest in this work.

\section{References}

1. British Medical Association. The right mix. BMA. 2015. Available from: https://www.bma.org.uk/features/therightmix/. Accessed August 30, 2019.

2. Office for Fair Access. Glossary. OFFA. 2018. Available from: https:// webarchive.nationalarchives.gov.uk/20180511111534/https://www. offa.org.uk/glossary/. Accessed August 30, 2019.

3. Medical Schools Council. Selecting for excellence final report. 2014. Available from: https://www.medschools.ac.uk/documents/1203/select ing-for-excellence-final-report.pdf. Accessed August 30, 2019.

4. Roberts N, Bolton P House of commons library: briefing paper: number 07914, 29 March 2017: medical school places in England from September 2018. 2017. Available from: http://research briefings.files.parliament.uk/documents/CBP-7914/CBP-7914.pdf. Accessed August 30, 2019.

5. Office for National Statistics; National Records of Scotland; Northern Ireland Statistics and Research Agency (2016): QS607EW - NS-SeC, 2011 Census aggregate data. UK Data Service (Edition: June 2016). DOI: $10.5257 /$ census/aggregate-2011-1. Available from: https://www. nomisweb.co.uk/census/2011/QS607EW/view/2092957703?rows= cell\&cols=rural_urban. Accessed August 30, 2019.

6. Office for Fair Access. Frequently Asked Questions. OFFA. 2018. Available from: https://webarchive.nationalarchives.gov.uk/ 20180511112150/https://www.offa.org.uk/students/frequently-askedquestions/. Accessed August 30, 2019.

7. Office for Fair Access. Breach List. OFFA. 2018. Available from: https://webarchive.nationalarchives.gov.uk/20180511112305/https:// www.offa.org.uk/universities-and-colleges/access-agreement-breaches/. Accessed August 30, 2019.

8. Gripper R, Joy I. What Makes a Good Charity? NPC's guide to charity analysis, New Philanthropy Capital. 2016. Available from: https://www. thinknpc.org/wp-content/uploads/2018/07/NPC_What-makes-a-goodcharity_Final-interactive.pdf. Accessed August 30, 2019.

9. Medical Schools Council. Implementing selecting for excellence. MSC. 2015. Available from: https://www.medschools.ac.uk/media/1207/select ing-for-excellence-2016-update-msc.pdf Accessed August 30, 2019.
10. Medical Schools Council. Selection alliance 2017 report. An Update on the Medical Schools Council's work on widening participation. MSC. 2017. Available from: https://www.medschools.ac.uk/media/ 2388/msc-selection-alliance-2017-report.pdf. Accessed August 30, 2019.

11. Medical Schools Council. A journey to medicine outreach guidance. MSC. 2014. Available from: https://www.medschools.ac. uk/media/1205/msc-a-journey-to-medicine-outreach-guidance.pdf. Accessed August 30, 2019.

12. General Medical Council. Corporate strategy and equality and diversity strategy 2014-17. GMC. 2013. Available from: https://www.gmc-uk. org/-/media/documents/05 - corporate-strategy-and-the-equality-anddiversity-strategy-2014-17_pdf-54300967.pdf. Accessed August 30, 2019.

13. Higher Education Funding Council for England. Expansion of undergraduate medical education places, invitation to make submissions. HEFCE. 2017. Available from: https://webarchive.nationalarchives. gov.uk/20180103171741/http://www.hefce.ac.uk/news/newsarchive/ 2017/Name,115256,en.html. Accessed August 30, 2019.

14. Jefferson L, Bloor K, Maynard A. Women in medicine: historical perspectives and recent trends. $\mathrm{Br}$ Med Bull. 2015;114(1):5-15. doi:10.1093/bmb/ldv007

15. Aston University, Birmingham. Widening participation, Aston Medical School. 2019 Available from: https://www2.aston.ac.uk/aston-medicalschool/widening-participation/index. Accessed August 30, 2019.

16. Kings College London. About outreach for medicine, outreach for medicine, studying with us, Faculty of Life Sciences and Medicine. 2019 Available from: https://www.kcl.ac.uk/lsm/study/outreach/ about/index. Accessed 30 August, 2019.

17. University of Southampton. BMBS Medicine and BMedSc (BM6, widening participation) (6 years), undergraduate. 2019. Available from: https://www.southampton.ac.uk/medicine/undergraduate/ courses/bm6_a102.page Accessed August 30, 2019.

18. University of Sheffield. Graduate entry medicine - MBChB (A101), applying for medicine, prospective undergraduates, The Medical School. 2019. Available from: https://www.sheffield.ac.uk/medicine/ prospective_ug/applying/graduateentry. Accessed August 30, 2019.

19. University of Aberdeen. Widening participation, medicine, undergraduate study. 2019 Available from: https://www.abdn.ac.uk/ smmsn/undergraduate/medicine/widening-participation.php. Accessed August 30, 2019.

20. Barts and the London School of Medicine and Dentistry. Medicine, undergraduate, Queen Mary University of London. 2019. Available from: https://www.qmul.ac.uk/smd/undergraduate/courses/ a101/. Accessed August 30, 2019.

21. University of Birmingham. Undergraduate medical and dental sciences courses, undergraduate, medical and dental sciences. 2019. Available from: https://www.qmul.ac.uk/smd/undergraduate/courses/ a101/. Accessed August 30, 2019.

22. University of Birmingham. Outreach and widening participation in the College of Medical and Dental Sciences, Outreach and Widening Participation, Medical and Dental Sciences. 2019. Available from: https://www.birmingham.ac.uk/university/colleges/mds/outreachwidening-participation/index.aspx. Accessed August 30, 2019.

23. University of Brighton and Sussex. Widening participation to medicine, information for schools, teachers and parents, about Brighton and Sussex Medical School. 2019. Available from: https://www.bir mingham.ac.uk/university/colleges/mds/outreach-widening-participa tion/index.aspx. Accessed August 30, 2019.

24. University of Bristol. MB ChB medicine (A100), medicine, undergraduate study. 2019. Available from: http://www.bristol.ac.uk/study/under graduate/2020/medicine/mb-medicine/. Accessed August 30, 2019.

25. University of Cambridge. Standard clinical course (MB BChir Standard), courses, education, School of Clinical Medicine. 2019. Available from: https://www.medschl.cam.ac.uk/education/courses/ standard/. Accessed August 30, 2019. 
26. University of Cardiff. Medicine, undergraduate, courses. 2019 Available from: https://www.cardiff.ac.uk/study/undergraduate/ courses/2020/medicine-mbbch. Accessed August 30, 2019.

27. University of Dundee. Medicine - gateway to medicine $\mathrm{MBChB}$, undergraduate. 2019. Available from: https://www.dundee.ac.uk/ undergraduate/medicine-gateway. Accessed August 30, 2019.

28. University of Edinburgh. Undergraduate medicine, Edinburgh Medical School. 2019. Available from: https://www.ed.ac.uk/med icine-vet-medicine/edinburgh-medical-school/medicine. Accessed August 30, 2019.

29. University of Exeter. BMBS medicine, medicine, undergraduate. 2019. Available from: http://medicine.exeter.ac.uk/study/ug/medi cine/. Accessed August 30, 2019.

30. University of Glasgow. MBChB at Glasgow Medical School, Medicine, Undergraduate. 2019. Available from: https://www.gla.ac. uk/undergraduate/degrees/medicine/\#tab=entry. Accessed August 30, 2019.

31. Hull and York Medical School. Medicine. 2019. Available from: https://www.hyms.ac.uk/medicine. Accessed August 30, 2019.

32. Imperial College London. MBBS/BSc Medicine, School of Medicine, Undergraduate. Available from: https://www.imperial.ac.uk/study/ug/ courses/school-of-medicine/medicine/\#entry-requirements. Accessed August 30, 2019.

33. Keele University. Medicine, 2020 entry, Undergraduate. 2019. Available from: https://www.keele.ac.uk/study/undergraduate/under graduatecourses/medicine/. Accessed August 30, 2019.

34. University of Lancaster. Medicine, medical school. 2019. Available from: https://www.lancaster.ac.uk/lms/medicine/. Accessed August 30, 2019.

35. Swansea University. Medicine (Graduate Entry), MBBCH, medicine courses, undergraduate. 2019. Available from: https://www.swansea. ac.uk/undergraduate/courses/medicine/mbbchgraduateentrymedicine/ . Accessed August 30, 2019.

36. St George's University of London. MBBS medicine, undergraduate, courses. 2019. Available from: https://www.sgul.ac.uk/study/under graduate/undergraduate-courses/medicine-mbbs/entry-criteria Accessed August 30, 2019.

37. University of St Andrews. Gateway to medicine, medicine, subjects, undergrad. 2019. Available from: https://www.st-andrews.ac.uk/sub jects/medicine/gateway-to-medicine/\#34462. Accessed August 30, 2019.

38. Queen's University Belfast. Medcine, undergraduate 2020, courses. 2019. Available from: http://www.qub.ac.uk/courses/undergraduate/ medicine-mb-a100/. Accessed August 30, 2019

39. University of Plymouth. BMBS Bachelor of Medicine, Bachelor of Surgery, undergraduate, courses. 2019. Available from: https://www. plymouth.ac.uk/courses/undergraduate/bmbs-bachelor-of-medicinebachelor-of-surgery. Accessed August 30, 2019.
40. University of Oxford. Medicine, pre-clinical, study. 2019. Available from: https://www.medsci.ox.ac.uk/study/medicine/preclinical. Accessed August 30, 2019.

41. University of Nottingham. Widening participation, school of medicine, routes into medicine, study with us. 2019. Available from: https://www.nottingham.ac.uk/medicine/study/medicine/widening-par ticipation.aspx. Accessed August 30, 2019.

42. University of East Anglia. MBBS Medicine, Norwich Medical School, Undergraduate, Study. 2019. Available from: https://www2. uea.ac.uk/study/undergraduate/degree/detail/mbbs-medicine? ga $=2$. 10436981.1140715226.1567167074-1801192441.1567167074. Accessed August 30, 2019.

43. University of Newcastle. Admissions, undergraduate, study with us, School of Medical Education. Available from: https://www.ncl.ac.uk/ sme/study/undergraduate/admissions/\#overview. Accessed on August 30, 2019 .

44. University of Manchester. Study medicine at Manchester, Medicine, Faculty of Biology, Medicine and Health. 2019. Available from: https://www.bmh.manchester.ac.uk/study/medicine/. Accessed August 30, 2019.

45. University of Liverpool. Medicine and surgery $\mathrm{MBChB}$, courses, undergraduate, study. 2019. Available from: https://www.liverpool. ac.uk/study/undergraduate/courses/medicine-and-surgery-mbchb/over view/. Accessed August 30, 2019

46. University of Leicester. Medicine MBChB, study, Leicester Medical School. 2019 Available from: https://le.ac.uk/medicine/study/mbchb. Accessed August 30, 2019.

47. University of Leeds. Widening access, undergraduate, School of Medicine. 2019. Available from: https://medicinehealth.leeds.ac.uk/ medicine-undergraduate/doc/widening-access-medical-schools. Accessed August 30, 2019.

48. University of Lancashire. Bachelor of Medicine and Bachelor of Surgery, Courses, Study. 2019. Available from: https://www. uclan.ac.uk/courses/bachelor_medicine_bachelor_surgery.php. Accessed August 30, 2019.

49. University College London. Medicine MBBS BSc, Undergraduate degrees, Undergraduate Courses. 2019. Available from: https:// www.ucl.ac.uk/prospective-students/undergraduate/degrees/medi cine-mbbs-bsc/2019. Accessed August 30, 2019.

50. University of Warwick. Medicine (MB ChB), Courses for 2020 Entry, Undergraduate, Study. 2019. Available from: https://warwick. ac.uk/study/undergraduate/courses-2020/medicine/. Accessed August 30, 2019.

51. The Medic Portal. Foundation Courses. 2019. Available from: https:// www.themedicportal.com/application-guide/choosing-a-medicalschool/foundation-courses/. Accessed August 30, 2019.
Advances in Medical Education and Practice

\section{Publish your work in this journal}

Advances in Medical Education and Practice is an international, peerreviewed, open access journal that aims to present and publish research on Medical Education covering medical, dental, nursing and allied health care professional education. The journal covers undergraduate education, postgraduate training and continuing medical education including emerging trends and innovative models linking education, research, and health care services. The manuscript management system is completely online and includes a very quick and fair peer-review system. Visit http://www.dovepress.com/testimonials.php to read real quotes from published authors. 